\title{
An Analysis of the Impacts of Universal Two-Child Policy on Urban Women's Career Development in China: Taking 420 Professional Women in Shenyang City as the Sample
}

\author{
Cui Huang \\ Faculty of Humanities and Social Sciences, Dalian University of Technology, Dalian, China \\ Email: huangcui42@dlut.edu.cn
}

How to cite this paper: Huang, C. (2018) An Analysis of the Impacts of Universal Two-Child Policy on Urban Women's Career Development in China: Taking 420 Professional Women in Shenyang City as the Sample. Open Journal of Social Sciences, 6, 343-353.

https://doi.org/10.4236/jss.2018.611026

Received: October 17, 2018

Accepted: November 27, 2018

Published: November 30, 2018

Copyright $\odot 2018$ by author and Scientific Research Publishing Inc. This work is licensed under the Creative Commons Attribution International License (CC BY 4.0).

http://creativecommons.org/licenses/by/4.0/

\begin{abstract}
Since January 2016, the universal two-child policy has been implemented in China, which is of great significance for balancing the sex ratio of newborns, and alleviating labor shortages and ageing population. The implementation of the universal two-child policy has also had an important influence on the career development of urban women. Drawing from the investigation with 420 professional women in Shenyang city through the questionnaire survey and semi-structured interviews, this article shows the positive and negative impacts of the new policy on urban women's career development. The policy helps the women be more cautious with their career choices and encourages their career growth. However, due to the lack of relevant policies based on gender security, it makes the women's employment situation more severe, their career development hampered, the contradiction between family and career more difficult to balance and so on. To alleviate these negative effects, we should construct a fair gender cultural pattern, strengthen legislation and improve the social security system of having a second child.
\end{abstract}

\section{Keywords}

Universal Two-Child, Urban Women, Career Development

\section{Introduction}

In January 2016, China began to implement the universal two-child policy to alleviate a series of problems caused by the traditional one-child policy. Undoubtedly, the new birth policy has had certain positive effects on population, health and economy in China: a more normal gender ratio, a large reduction in abor- 
tion, and a considerable limitation of the problems of labor shortages and population ageing [1]. However, from the point of view of urban professional women who are the important subjects of population reproduction, besides many positive impacts of this policy, its negative effects should be paid more attention to.

\section{Literature Review}

\subsection{Foreign Scholars' Research}

As the policy has not been implemented for a long time, there have not been a large number of studies on this issue in the academic circles. Foreign scholars' research mainly focuses on the influencing factors on career development of various types of women. For example, one study mentioned about the significant increase in the proportion of Austrian female scholars in leadership positions in universities, and explored different career development models for women [2]. The career development of British female football players was analyzed in another article [3]. One different paper discussed the success of black female teachers and their early career development. The professional knowledge and professional personal network of writing and publishing are believed to be crucial to the success of this group [4]. Some scholars also discussed the influence of gender barriers on the career development of females in the legal profession, and then analyzed the differences between male and female career patterns [5].

\subsection{Domestic Scholars' Research}

The effects of the universal two-child policy have been discussed by many scholars in China. The research content is roughly divided into three types:

The first type of research concentrates on the impact of this policy on women's employment. Some scholars believe that the implementation of the universal two-child policy can bring some negative impacts on women's work and life [6]. It weakens women's power in marriage, and affects negatively on their reproductive autonomy [7]. In addition, the discrimination faced by females in the employment process tends to be more serious [8] [9], and their promotion and career prospects are also affected [10]. Therefore, it is suggested that the protection of women's employment rights should be strengthened [11] [12] and childbearing should be encouraged by increasing state financial subsidies and reducing family parenting costs [13].

The second type of research primarily discusses women's fertility willingness under the universal two-child policy. There are a considerable number of studies concerning about this issue. For instance, a sample survey was conducted in order to examine the willingness and influencing factors of the second birth of the married population in five provinces and cities in China [14]. A qualitative study on the concept of fertility of professional women under the universal two-child policy was also conducted with the purpose of finding out the main reasons why professional women have or refuse a second child [15]. In relation to the fertility willingness of professional women, one paper analyzed its influencing factors 
and causes in having a second child. [16] Another study proved that women of childbearing age working in government agency and institutions have the higher rate of having a second child than in the private and foreign-funded enterprises [17].

The third type of research focuses on the problems of people's health after the introduction of the two-child policy from a medical perspective. For example, it is considered that the Zika virus may have a negative impact on the universal two-child policy, which is a new challenge to China [18]. Some scholars also explored the uterine health problems of women under the universal two-child policy [19].

Different from the above researches, this article concentrates on the urban professional women. As they live in cities and have professional positions, the birth of the second child has a greater influence on their lives, especially on their career development than the rural and urban unemployed women. The article takes 420 professional women from Shenyang city, Liaoning province as the sample, and uses the data from field research as data support to investigate both positive and negative effects in the implementation of the universal two-child policy on the career development of urban professional women with the goal of providing the enlightening reference for improving supporting measures of this policy.

\section{Research Methods}

\subsection{Questionnaire Survey and Semi-Structured Interview Method}

The survey area was mainly in the urban areas of Shenyang city in China. First of all, 420 questionnaires were distributed to the professional women in the city, including 300 paper questionnaires and 120 electronic questionnaire and then 414 questionnaires were returned. There were 407 valid questionnaires, and the recovery rate of valid questionnaires reached $96.9 \%$. Next, on the basis of the questionnaire survey, 8 typical survey subjects were selected to be interviewed to make up for some deficiencies in the questionnaire survey. The following question were asked, such as "Do you know the universal of two-child policy? What impact do you think this policy take to your lives? Will you born the second child? if you will, please tell me the reason. Do you think having a second child affects your career development? Please talk about them in details. What do you think the government or country can do to increase the enthusiasm of people to have a second child?"

\subsection{Scientific Test}

In this article, Cronbach's $\alpha$ coefficient was used to test the reliability of the questionnaire. The Cronbach's $\alpha$ coefficient of the questionnaire was 0.813 , which was greater than 0.8 . This indicates that the questionnaire has a clear structure and high credibility.

According to the "sample basic situation" in Table 1, the female population in this survey was at the age from 21 to 50 . The majority of them were between the 
Table 1. Sample basic situation $(\mathrm{N}=407)$.

\begin{tabular}{|c|c|c|c|}
\hline & Description entry & Frequency & Percentage (\%) \\
\hline \multirow{3}{*}{ Age } & 20 to 29 years old & 203 & 49.81 \\
\hline & 30 to 39 years old & 173 & 42.48 \\
\hline & 40 years old and above & 31 & 7.70 \\
\hline \multirow{4}{*}{$\begin{array}{c}\text { Marriage and } \\
\text { childbearing status }\end{array}$} & Unmarried and childless & 35 & 8.56 \\
\hline & Married and childless & 85 & 21 \\
\hline & Married and a child & 211 & 51.78 \\
\hline & Married and two children & 76 & 17.67 \\
\hline \multirow{5}{*}{ Education level } & Junior high school and below & 21 & 5.28 \\
\hline & $\begin{array}{l}\text { High school and } \\
\text { technical secondary school }\end{array}$ & 78 & 19.14 \\
\hline & Junior college & 86 & 21.13 \\
\hline & Undergraduate & 163 & 40.08 \\
\hline & Graduate and above & 59 & 14.37 \\
\hline \multirow{5}{*}{ Work unit } & Organs and institutions & 83 & 20.43 \\
\hline & State-owned enterprise & 105 & 25.86 \\
\hline & Private enterprise & 78 & 19.04 \\
\hline & Individual business & 76 & 18.71 \\
\hline & Unemployed & 65 & 15.96 \\
\hline
\end{tabular}

ages of 20 and 39, accounting for $92.29 \%$ of the total. The women of this age were at the best fertility stage and were involved in the universal two-child policy. In order to ensure the rigor and scientific nature of the research, this survey also included a small proportion of women aged 40 and over, accounting for $7.7 \%$.

In terms of the status of marriage and childbearing, $91.44 \%$ of the surveyed respondents were married women, in which $51.78 \%$ of them belonged to the "married and have one child" group. In fact, this part of the survey population is considered as the focus of the study because they are the most likely to have a second child in the short term. In order to make the survey more comprehensive, $8.56 \%$ of unmarried urban women were also covered.

With regard to the educational level of the sample subjects, it was divided into five levels of education from "junior high school and below" to "graduate and above". The proportion of women with undergraduate and higher education was almost equal to that of women with junior college and below. These two parts are the main body of urban professional women, which could make the survey more scientific.

Regarding to the work unit, the survey covered almost the working places where urban professional women have been working, including organs and institutions, state-owned enterprises, private enterprises, individual businesses and other departments. 


\section{The Impacts of Universal Two-Child Policy on Urban Women's Career Development}

The introduction of any policy has various kinds of effects, including both positive and negative effects. The universal two-child policy is no exception.

\subsection{Positive Impacts}

The research results show that the second birth has some positive impacts on the career development of urban professional women. Under the new fertility policy, the urban women are likely to make more prudent and comprehensive decisions on their initial career choices. In addition, facing with more life tasks is a good way for them to stimulate their own potential and career growth.

\subsubsection{Women's Occupation Choices Are More Carefully Considered}

Some women believe that having a second child is not a barrier to their career development; instead, it can help them be more cautious with their career choices and create more scientific plans for their own career. For example, when being asked how the universal two-child policy affected her career development, the interviewee No. 4, who is a married and childless 25 -year-old woman and works as a government agency staff member, answered like this:

Although I haven't had a baby yet, I want to have two children in the future. I don't have a lot of work pressure and have enough time for rest. I think having two children is not a big problem because my parents and babysitters can help me to take care of the babies and my working place also has welfare measures to moms with a second child. Moreover, my job is quite stable, and I don't really want to get promotion. Now I can meet with a good policy and be happy to have two children.

The interviewee is a typical example for the women who have little work pressure and no strong desire for promotion, and want to have two children. Such women can adapt quickly when they return to their workplace after their maternity leave and realize that the universal two-child policy does not have any bad influences on their career development. In contrast, this policy assists them in having a more comprehensive consideration in choosing the professions which truly interest them and have regular working schedules, conducting more scientific and effective career management and seeking the best balance between family and career.

\subsubsection{Women's Career Growth Is Encouraged}

To a certain extent, the universal two-child policy also has an incentive effect on women's career growth. Some interviewees have realized that giving birth as a necessary experience in life inevitably conflicts with their career development. In this regard, they believe that it is better for them to face with the difficulties instead of being helpless. They should discover their own abilities and values, find the right positions for their careers, and look for auxiliary means to improve 
themselves in stages. After reasonably arranging time and having their own clear development goals, they can better stimulate their potential in all aspects and make great job achievements. This is no doubt a rational reflection of modern professional women's on social gender issues and a profound understanding of female self-realization.

\subsection{Negative Impacts}

\subsubsection{The Employment Situation of Urban Women Becomes Tougher}

It is known that being employed is the starting point for women's career growth. According to the survey, the universal two-child policy undoubtedly aggravates women's disadvantages in job hunting. For protecting the labor rights and interests of women, China has clearly stipulated that women have equal employment rights with men in the Constitution, Labor Law of the People's Republic of China and Law of the People's Republic of China on the Protection of Rights and Interests of Women. However, as women and men are physically different, women are not appropriate with jobs that require physical strength and frequent travel. This results in the fact that women's employment range is much smaller than that of men. Furthermore, many employers tend to favor men than women in their process of recruitment because they worry about the burden of paid maternity leave policy for female employees while the government has almost no corresponding compensation measures in this regard. Therefore, after the implementation of the two-child policy, in most of the job interviews, female job-hunters are explicitly asked whether they consider having a second child. If the answers are "yes", they are often refused to be hired. It can be said that under the influence of the new fertility policy, the "married and one child" women group who used to have a comparative advantage in the job search process have gradually lost favors from employers, and the other groups (the "unmarried" women and the "married and childless" women) who were in a very tough employment condition have found the competition of employment more and more difficult.

\subsubsection{Women's Career Progression Is Hindered}

It is certain that having a second child affects more or less most urban women's career development. Figure 1 shows that the majority of the surveyed women (nearly 70\%) believe that having a second child has certain negative impacts on their career development while the small proportion of them (30\%) think that there is no effect. The most significant negative impact concerned by $57.94 \%$ of the respondents is "reduction in promotion opportunities". The other two negative impacts concerned by $15.95 \%$ and $9.31 \%$ of the respondents respectively are "high probability of dismissal from employment" and "reduction in salary".

The results above indicate that the introduction of the universal two-child policy may become the real barrier that hinders women's career development; especially there is high possibility of the loss of promotion chances for women who intend to have a second child. It is known that the ages of 25 to 39 are the 


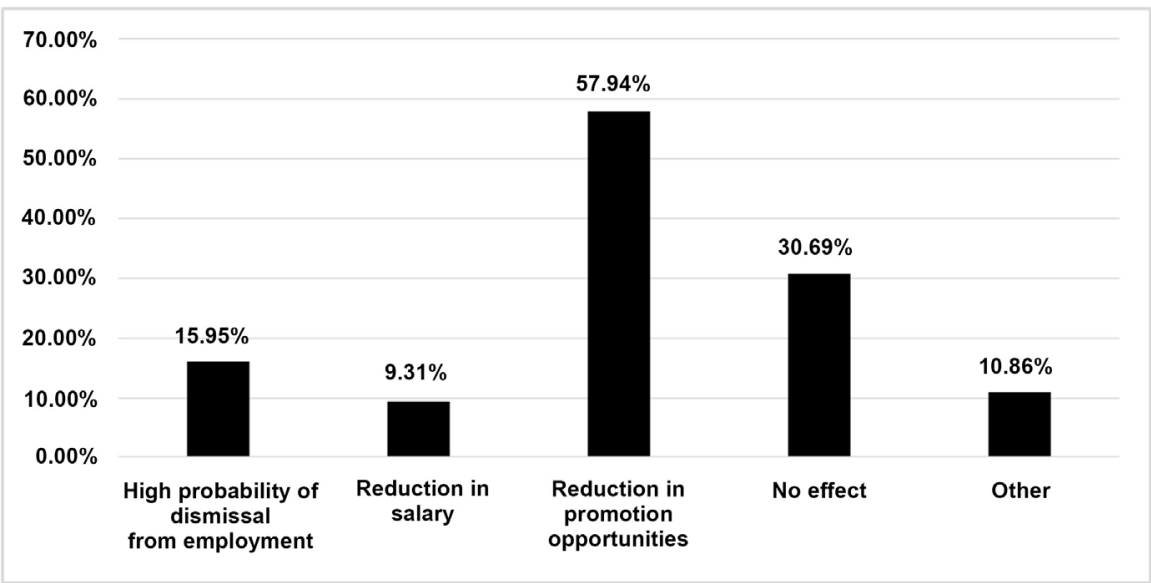

Figure 1. Statistical chart of the impact of second birth on urban female career development $(\mathrm{n}=407)$.

most important period for women to develop their career, and also the best period for them to give birth. This coincidence makes women face with the conflicts between childbearing and career development. In reality, if women decide to have a second child, they should cost a lot of their time and energy for the long process of re-pregnancy, maternity leave and body recovery. This can lead to the loss of their competitive advantage in the workplace. With the second birth, women in state-owned enterprises and institutions are likely to miss their chances of promotion while women in private companies may even face the risk of unemployment.

\subsubsection{The Conflict between Family and Career Is More Difficult to Balance}

The double burden of balancing work life and family life, in recent years, has presented a significant challenge for professional women in China. It is difficult for them to meet the expectations of the two roles above under the condition of their limited time and energy, thus this creates conflict. In fact, the conflict between career and family of urban women has increased in a higher degree and has become more difficult to balance after the implementation of the universal two-child policy. On the one hand, in order to get a good and high-paid job, professional women often experience a lot of work pressure. On the other hand, their responsibilities about their children can be increased by double if they have a second child. Figure 2 shows survey of women's evaluation of difficulty levels in balancing between work and family in case they have another baby. From the figure, we can see that about $75 \%$ of the surveyed women believe that it is "more difficult" or "very difficult" to balance while only $25.81 \%$ of them think that there is no difficulty. This result points out that most urban professional women find difficulty in the work-family balance after their second birth. Hence, most times they have to choose between the two, career or family. If they decide to place more importance on work, they may lose the opportunity of happiness of having two children. On the contrary, if they make the choice that fulfills their hopes or dreams about having two children, they will sacrifice the golden age of their career growth, which also definitely affects their income and self-realization. 


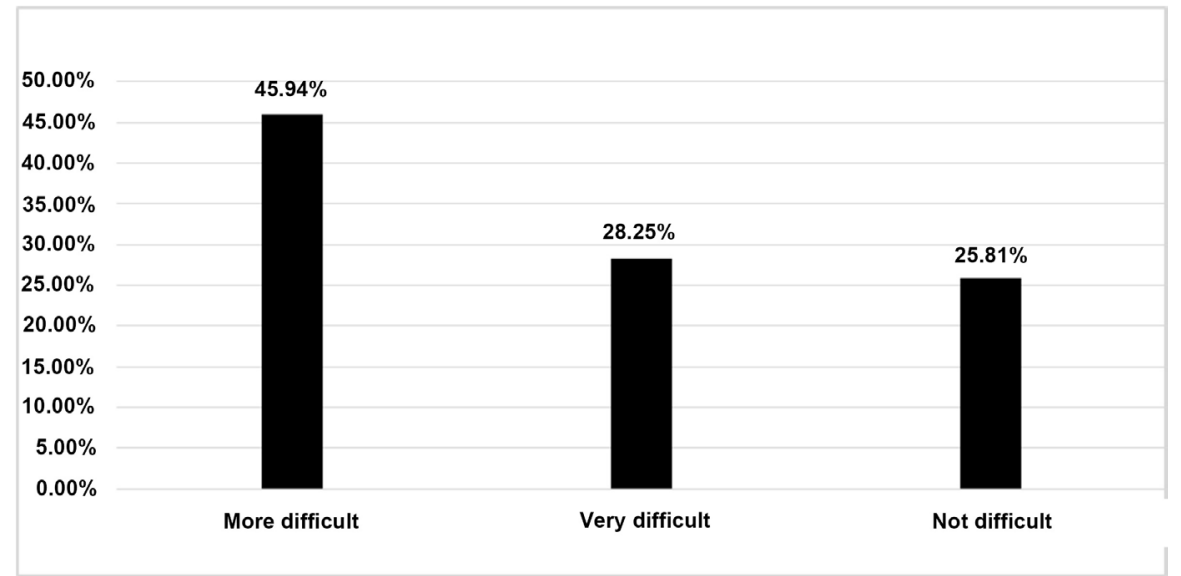

Figure 2. Statistical chart "How difficult do you find to balance between family and work if you have a second child?" ( $\mathrm{n}=407)$.

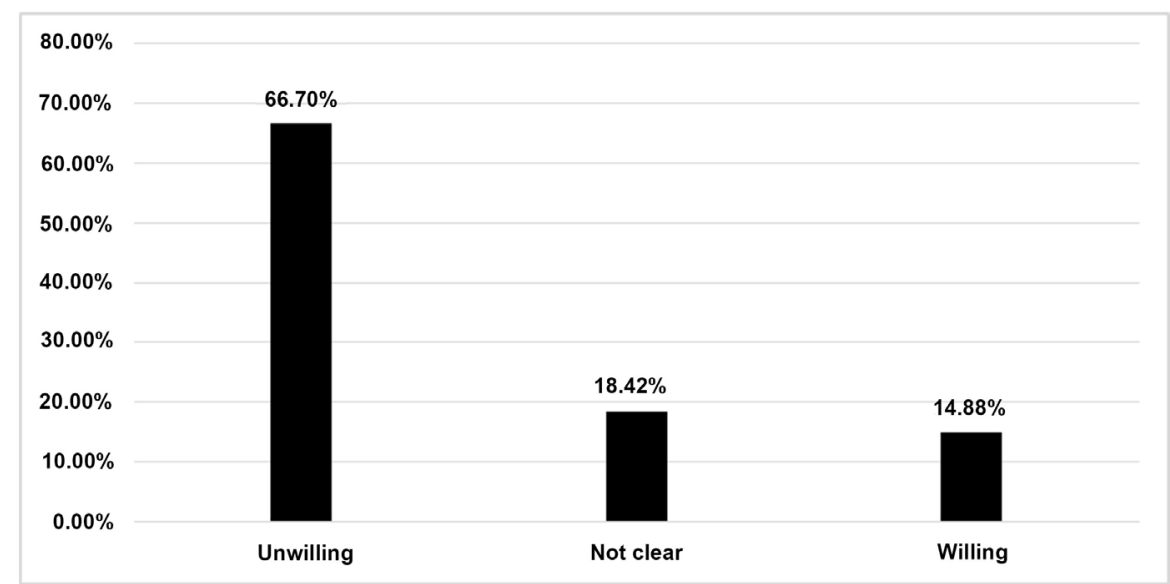

Figure 3. Statistical chart "Will you give up your career in order to have a second child?" $(n=407)$.

At the same time, this survey also investigates whether women are willing to give up their career in order to have a second child. Figure 3 shows that the proportion of women who choose "unwilling" (66.70\%) is much higher than the number of women who choose "willing" and "not clear" (only $14.88 \%$ and $18.42 \%$ respectively). The group of the respondents who choose "not clear" are those who still wonder about their choice. The result reveals that most urban women are not willing to have a second kid, which fully reflects the independent consciousness and spiritual pursuit of women in modern cities.

The interviewee No. 8 is a typical case of this issue. She is 32 years old, has a 6-year-old daughter and works in a private enterprise. She ever thought about having a second child after the new birth policy was introduced. However, then she decided to give up that idea for her career progression. When being asked about the intention to have a second kid, she said like this:

I ever thought about that, and was struggling with whether or not to have another child. At that time, our department leader was pregnant her second 
baby and then she had a conversation with our manager. The result was that she might not keep her current employment position and also got a large reduction in salary. Luckily, she was still happy with her decision. A few days later, I was offered to get a promotion by the manager with one condition that I couldn't have a second baby. As having been waiting for that opportunity for so long, I had to give up my intention to have another child. I think that it was the only chance for me to be promoted and I didn't want to lose it.

\section{Conclusions and Suggestions}

The research results show that the universal two-child policy has both positive and negative impacts on urban professional women's career advancement, and the negative seem to outweigh the positive. The women have to face with the number of problems if they have a second birth: the greater difficulty in job hunting, the reduction in promotion opportunities or even the risk of unemployment, and the double burden of work-family balance. Therefore, together with the introduction of the universal two-child policy, the government should make a difference in the construction of the gender structure, legislation, social security system and so on in order to enhance the fertility willingness of professional women and to realize the positive roles of the two-child policy in population development and economic prosperity. Some concrete action measures for this should be carried out as follows:

First, a fair gender cultural pattern should be constructed by actively promoting gender mainstreaming, and introducing civic awareness or gender awareness into the decision-making process of government departments and the media communication process so that women can improve their social status. Second, at the legislative level, the introduction and implementation of the Anti-Employment Discrimination Law should be vigorously promoted, and the refusal to implement the Labor and Employment Law and other relevant laws should be severely punished to ensure women's bright career prospects and their freedom from the worry of having a second child. Third, it is essential to improve the social security system of the universal two-child policy. For example, the government should give more financial support to two children families, and implement fiscal and tax policies which are beneficial to the protection of female labor rights and interests. At the same time, parental leave rights should be extended to fathers during maternity leave in order to encourage men and women to share their family responsibilities. Only by this kind of support from their husbands, women can have more time and energy for their employment, and especially for their career development.

\section{Funding}

This paper is supported by General Project of the National Social Science Fund in China "Research on the Organizational Development of Rural Women in Ru- 
ral Governance" (17BZZ065) and the Liaoning Province Academy of Social Sciences planning fund project (key project) "Research on the promotion paths of Liaoning rural left-behind women's organizing” (L15ASH002).

\section{Acknowledgements}

I would like to express my sincere gratitude to my student, Qianchu Liu for her hard work with the statistics data processing and some relevant jobs for this article.

\section{Conflicts of Interest}

The author declares no conflicts of interest regarding the publication of this paper.

\section{References}

[1] Zeng, Y. and Hesketh, T. (2016) The Effects of China's Universal Two-Child Policy. Lancet, 38, 1930-1938. https://doi.org/10.1016/S0140-6736(16)31405-2

[2] Fritsch, N.-S. (2016) Patterns of Career Development and Their Role in the Advancement of Female Faculty at Austrian Universities: New Roads to Success? High Educated, 72, 619-635. https://doi.org/10.1007/s10734-015-9967-6

[3] Gledhill, A. and Harwood, C. (2015) A Holistic Perspective on Career Development in UK Female Soccer Players: A Negative Case Analysis. Psychology of Sport and Exercise, 21, 65-77. https://doi.org/10.1016/j.psychsport.2015.04.003

[4] Jones, T.B. and Osborne-Lampkin, L. (2013) Black Female Faculty Success and Early Career Professional Development. The Negro Educational Review, 64, 59-75.

[5] Krakauer, L. and Chen, C.P. (2003) Gender Barriers in the Legal Profession: Implications for Career Development of Female Law Students. Journal of Employment Counseling, 40, 65-79. https://doi.org/10.1002/j.2161-1920.2003.tb00857.x

[6] Mi, Z. (2017) Analysis of the Impact of Universal Two-Child on Female Employment. Hebei Enterprise, 2, 101-102.

[7] Qian, Y. and Jin, Y.A. (2018) Women's Fertility Autonomy in Urban China: The Role of Couple Dynamics under the Universal Two-Child Policy. Chinese Sociological Review, 50, 275-309. https://doi.org/10.1080/21620555.2018.1428895

[8] Shu, X. (2018) Analysis of the Impact of Universal Two-Child Policy on Female Employment and its Response. China International Business, 2, 92-93.

[9] Xiao, W., Li, S.M. and Chong, Y.X. (2017) The Influence of the Universal TwoChild Policy on Female "Birth" and "Promotion". Labor Security World, 18, 24.

[10] Zhang, Y. and Zhang, X.W. (2017) Research on the Impact of the Universal TwoChild Policy on the Employment of Female. Modern Business Trade Industry, 33, 131-132.

[11] Yin, X.L. (2018) Protection of Female Employment Rights under the Policy of "Universal Two-Child”. Legal System and Society, 4, 158-159.

[12] Zhao, F.H. (2018) Analysis on the Protection of Female Labor Employment Rights under the Two-Child Policy in China. Legal System and Society, 25, 143-144.

[13] Li, J. (2017) Research on Female Employment Shock and Mitigation Countermeasures under the Policy of "Universal Two-Child". Academic Journal of Jinyang, 2 , 139-141. 
[14] Yang, X.Y. (2017) Investigation on the Fertility Desire and Its Influencing Factors of the Second Birth in China under the "Universal Two-Child" Policy. Journal of Jiamusi Vocational College, 1, 468.

[15] Tao, W.W., Chen, Z.N., et al. (2017) The Qualitative Research of Professional Female Fertility View under the Background of Comprehensive Two-Child Policy. Nursing Research of China, 26, 3310-3314.

[16] Li, W. (2018) Analysis on the Influencing Factors and Reasons That Affect the Willingness of Professional Female to Have a Second Child. Chinese Journal of Women and Children Health, 3, 49-50.

[17] Long, S.Q. and Chen, H.L. (2017) The Influence of the Employment Status of Urban "Double Non-One Child" Female of Childbearing Age on the Choice of Second Child Birth. Journal of Southeast University (Philosophy and Social Science), 3, 83-90, 147.

[18] Zhou, P.C., Wang, J., et al. (2016) Zika Vivus May Affect the Universal Two Child Policy: A New Challenge for China. PLOS Neglected Tropical Diseases, 11, 1-4.

[19] Zeng, C.J., Yang, M.Y., et al. (2018) Placenta Accreta Spectrum Disorder Trends in the Context of the Universal Two-child Policy in China and the Risk of Hysterectomy. International Journal of Gynecology \& Obstetrics, 140, 312-318. 